\title{
Erosion and Mechanical Performance Analysis on NFRPC Filled with Biochar
}

\author{
M.S. Abilash, V. Arumugaprabu, C. Bennet
}

\begin{abstract}
This work dealt with the fabrication of natural fibres reinforced polymer composites with the biochar as filler. Composites are prepared using compression moulding machine. Pineapple fibre was used as reinforcement and vinyl Ester resin was used as a matrix. Pineapple fibre of length 50 mm and weight as $50 \%$ were taken for the study. The prepared composites were subjected to erosion and mechanical performance studies and based on the results obtained, the prepared composites were suggested for suitable applications.
\end{abstract}

Keywords: Natural Fibre, Vinyl ester resin, Biochar.

\section{INTRODUCTION}

$\mathrm{N}$ atural fibres have gained more attention of the international research people in the last few years. Composites are made using natural fibre as reinforcement and resin as matrix. The reinforcement increases the mechanical properties of the matrix. It is hard, strong and stiff when compared to the matrix [1]. The natural fiber composites have become an alternative to glass-fiber reinforced composites especially in automobile applications. Natural fiber reinforced composites have gained more attraction in automotive industries [2]. This project deals with the fabrication of natural fibres reinforced polymer composites with the bio char as a filler. Composites are prepared using compression moulding machine. Pineapple fibre used as reinforcement and vinyl Ester resin used as a matrix. Pineapple fibre of length $50 \mathrm{~mm}$ and weight is $50 \%$ taken for the study.

Biochar is used as potential addition in composites. The improvement in mechanical properties of the composites is mainly because of movement of polymer into the pores and by better dispersion of biochar particles in the matrix [3]. The authors studied the possibility of the reinforcement potential of chars from different sources in epoxy composites [4]. Biochar is used to prepare composites to enhance mechanical porperties due to its special structure. Many researchers have prepared composites with biochar as filler,

Revised Manuscript Received on December 16, 2019

* Correspondence Author

M. S. Abilash, School of Automotive and Mechanical Engineering. Kalasalingam Academy of Research and Education, Krishnankoil-626 126, India. Email: abilash.nivas@gmail.com

V. Arumugaprabu, School of Automotive and Mechanical Engineering Kalasalingam Academy of Research and Education, Krishnankoil-626 126, India. Email: v.arumugaprabu@klu.ac.in

C. Bennet*, School of Automotive and Mechanical Engineering. Kalasalingam Academy of Research and Education, Krishnankoil-626 126, India. Email: benutha24@rediffmail.com the result proved that biochar is playing a vital role to improve the mechanical properties of the composites [5]. An attempt is made to study the mechanical and erosion performance of pineapple fibre reinforced biochar (produced from corncob) composites.

\section{EXPERIMENTAL METHODOLOGY}

\section{A. Material used}

\section{Corncob}

A corncob, likewise called cob of corn, is the focal centre of an ear of corn. It is the piece of the ear on which the parts develop. The ear is additionally considered a "cob" or "shaft" yet it isn't completely a "post" until the ear is shucked, or expelled from the plant material around the ear.

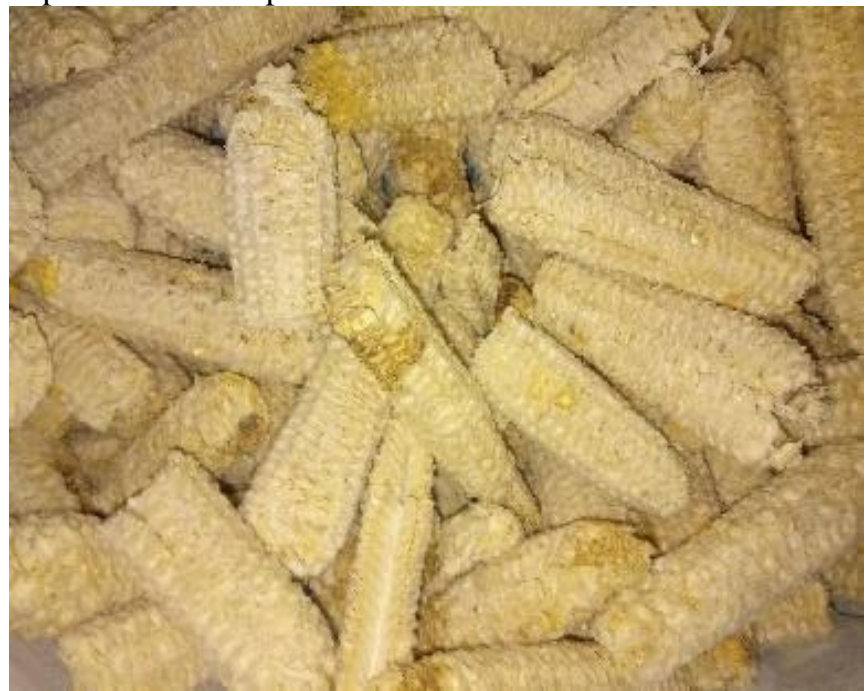

Fig.1.Corncob

\section{Pineapple fibre}

Pineapple fibre is a fibre produced using the leaves of a pineapple plant and is generally utilized in the Philippines. It is now and again joined with silk or polyester to make a material texture. Since pineapple fibre is from a leaf, the leaf must be cut first from the plant. At that point the fibre is pulled or split far from the leaf. Most leaf filaments are long and to some degree solid. 


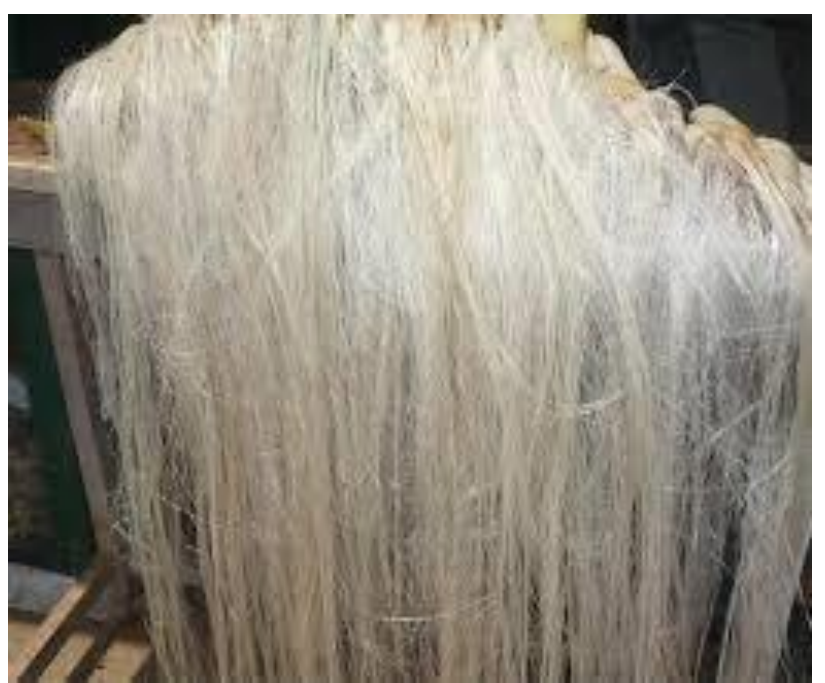

Fig.2. Pineapple Fibre

\section{Vinyl ester resin}

Vinyl ester gum, or regularly just vinyl ester, is a sap delivered by the desertification of an epoxy gum with acrylic or meth acrylic acids. The "vinyl" bunches allude to these ester substituents, which are inclined to polymerize [5]. This thermoses material can be utilized as an option in contrast to polyester and epoxy materials as the thermoset polymer network in composite materials, where its qualities, qualities, and mass expense are middle among polyester and epoxy. Vinyl ester has lower tar thickness than polyester and epoxy.

\section{Fabrication of Composites}

The pineapple fibre is cut approximately into optimum fibre length of $50 \mathrm{~mm}$. The vinyl ester resin is used as a matrix.300ml of vinyl ester resin is taken in a beaker and mixed with $5 \%$ of biochar along with the resin and the process take 20 minutes. Once the process is finished, hardener is added to the resin. This isadopted for the $1 \mathrm{st}$ sample, and similarly for $30 \%$ and $45 \%$ samples (2nd and 3rd samples). Fibres are arranged in random orientation. At first, vinyl ester resin is poured in the mould made of EN90 steel with the dimensions of $180 \times 130 \times 3 \mathrm{~mm}$. After placing the mould in the machine, it is compressed by applying curing pressure of $15 \mathrm{MPa}$ and optimum curing temperature (300C).

\section{TESTING OF COMPOSITES}

\section{A. Tensile test}

Tensile strength is a measure of a material's ability to resist being pulled apart. Universal Testing Machine (Instron series - 3382) is used to perform tensile test. ASTM D 3039 is adopted. A thickness of $3 \mathrm{~mm}$ is maintained. The tensile test is performed on all the five samples and the average is taken.

\section{B. Flexural test}

$50 \mathrm{~mm}$ span is taken and cross head speed is maintained as 2 $\mathrm{mm} / \mathrm{min}$. ASTM D 790 standards are followed. The test is performed on all the five samples and the average is taken.

\section{Erosion test}

Air jet erosion tester was used to conduct the erosion studies on the fabricated biochar filled NFRPC.

\section{RESULTS AND DISCUSSION}

\section{A. Tensile strength}

The effect of biochar on tensile strength of pineapple fibre reinforced vinyl ester composites fabricated with room temperature is shown in Figure 1. By the addition of biochar along with Pineapple fibre it was noted that the strength goes on decreasing with the increase in biochar weight percentage. Biochar of weight percentage $15 \%$ has a tensile strength of $16 \mathrm{MPa}$ which decreases in the case of $30 \%$ wt. i.e., $12 \mathrm{MPa}$ and remains the same for $45 \% \mathrm{wt}$. This is due to the reason of distribution of the biochar particles which is not uniform. Inability of matrix material to hold huge amount of reinforcements. This causes decrease in tensile strength as the reinforcement increases.

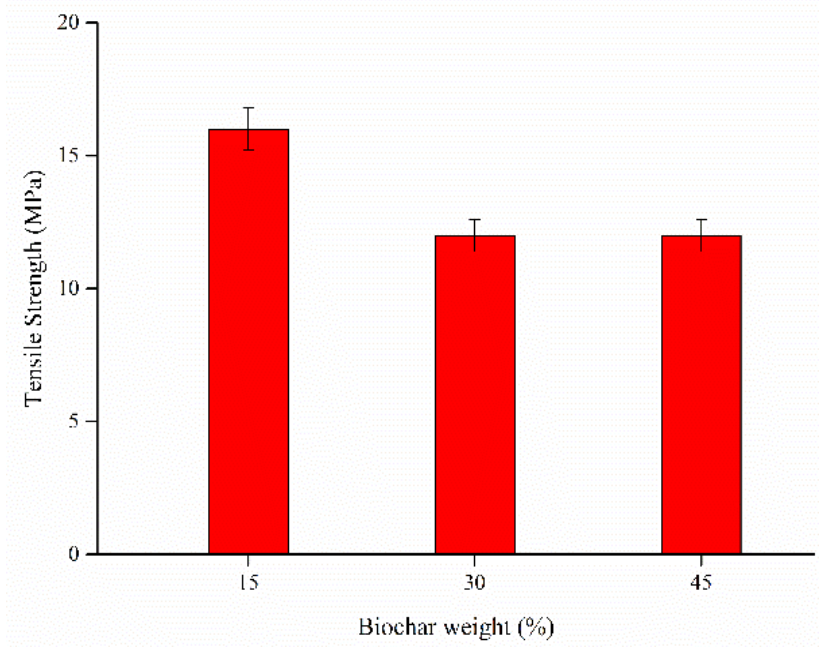

Fig.3. Effect of chemical treatment on tensile strength and modulus of treated pineapple fibre $(50 \mathrm{~mm}, 50 \mathrm{wt}$. $\%$ ) reinforced vinyl ester composites

\section{B. Flexural strength}

The effect of biochar on flexural strength of pineapple fibre reinforced vinyl ester composites fabricated with room temperature is shown in Figure 4 where the same phenomenon like tensile strength is achieved. The addition of more and more biochar weight percentage decreases the flexural strength ranging from $48 \mathrm{MPa}$ to $35 \mathrm{MPa}$.

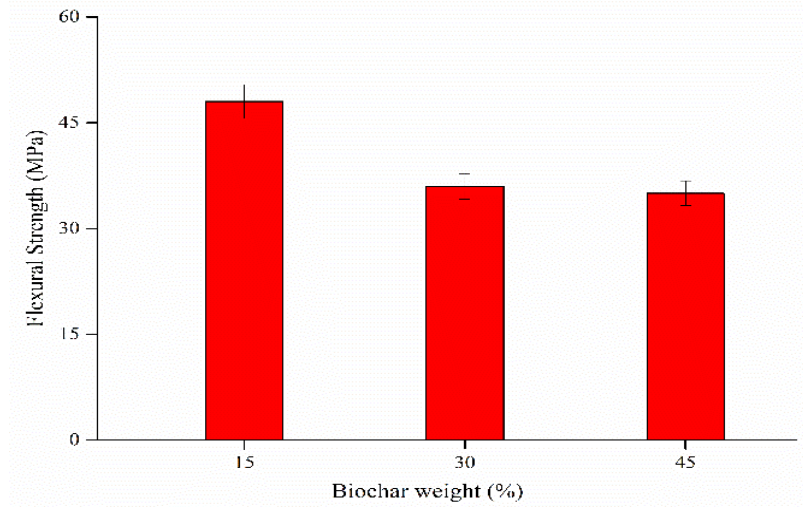

Fig.4. Effect of Biochar addition on flexural strength of pineapple fibre $(50 \mathrm{~mm}, 50 \mathrm{wt}$. \%) reinforced vinyl ester composite.

Published By

Blue Eyes Intelligence Engineering \& Sciences Publication 


\section{Erosion studies}

The effect of biochar on erosion rate of pineapple fibre reinforced vinyl ester composites fabricated with room temperature is shown in Table 1. Experiment was conducted using L9orthogonal array. From the Table 1 it was observed that erosion rate was maximum for $10 \mathrm{wt}$ \% biochar filled NFRP composite with impact velocity and impact angle as $125 \mathrm{~m} / \mathrm{s}$ and $30^{\circ}$. Minimum erosion rate was observed for 15 wt. \% biochar filled composite with impact velocity $90^{\circ}$. When the erosion rate is minimum at $90^{\circ}$ impact angle the material behaves as ductile material. When adding biochar to the composite from $5 \mathrm{wt} . \%$ to $15 \mathrm{wt}$. \% the material changes its behaviour to erosive wear as ductile to brittle material.

Table 1: Erosion rate for the Biochar filled NFRPC

\begin{tabular}{|c|c|c|c|c|}
\hline S. No & $\begin{array}{c}\text { Filler } \\
\text { Content } \\
(\text { wt. } \%)\end{array}$ & $\begin{array}{c}\text { Impact } \\
\text { Velocity } \\
(\mathbf{m} / \mathbf{s})\end{array}$ & $\begin{array}{c}\text { Impact } \\
\text { Angle } \\
\left({ }^{\circ}\right)\end{array}$ & $\begin{array}{c}\text { Erosion } \\
\text { Rate } \\
\left(\mathbf{1 0}^{-5}\right) \\
(\mathbf{g} / \mathbf{g})\end{array}$ \\
\hline 1. & 5 & 100 & 30 & 8.48 \\
\hline 2. & 10 & 125 & 60 & 11.21 \\
\hline 3. & 15 & 150 & 90 & 1.81 \\
\hline 4. & 5 & 100 & 60 & 3.93 \\
\hline 5. & 10 & 125 & 90 & 8.78 \\
\hline 6. & 15 & 150 & 30 & 6.06 \\
\hline 7. & 5 & 100 & 90 & 10.33 \\
\hline 8. & 10 & 125 & 30 & 21.51 \\
\hline 9. & 15 & 150 & 60 & 6.36 \\
\hline
\end{tabular}

\section{CONCLUSION}

From the mechanical and erosion studies carried on the biochar filled pineapple fibre reinforced vinyl ester composites, the following conclusions were made:

* Mechanical properties like tensile and flexural strength decreases as the biochar loading increases for $50 \mathrm{wt} . \%$ and $50 \mathrm{~mm}$ fibre length pineapple reinforced NFRP composite. It is because of inadequate quantity of matrix to hold the biochar firmly to the whole composite.

* Erosion resistance of the composite increases as the biochar content increases from $5 \mathrm{wt}$. $\%$ to $15 \mathrm{wt}$. \%. The material behaves brittle as the biochar content increases which are proved with the maximum erosion rate at $30^{\circ}$ impact angle.

\section{ACKNOWLEDGMENT}

The authors thank the Centre for Composite Materials, Kalasalingam Academy of Research and Education, Krishnankoil for providing assistance to carry out this work.

\section{REFERENCES}

1. R.M.N. Arib, S.M. Sapuan, M. Ahmad, M.T. Paridah, and H.M.D. Khairul Zaman, "Mechanical properties of pineapple leaf fibre reinforced Polyproplyene composites", Journal of Materials and Design, Vol. 27 (5), 2006, $391-396$
2. L.Uma Devi, S.S. Bhagawan, and Sabu Thomas, "Mechanical properties of pineapple leaf fibre-reinforced polyester composites", Journal of Applied Polymer Science, Vol.64, 1997,1739 - 1748.

3. T.Vaisanen, A.Haapala, R.Lappalainen and L.Tomppo, "Utilization of agricultural and forest industry waste and residues in natural fiber-polymer composites: a review," Waste Management, Vol.54, 2016 , $62-73$.

4. G.Ahmetli, S.Kocaman, I.Ozaytekin and P.Bozkurt, "Epoxy composites based on inexpensive char filler obtained from plastic waste and natural resources", Polymer Composites, Vol. 34 (4), 2013, 500 - 509

5. S.Ikram, O.Das, D.Bhattacharyya, “A parametric study of mechanical and flammability properties of biochar reinforced polypropylene composites", Composites Part A Applied Science Manufacturing, Vol. 91, 2016, 177-188.

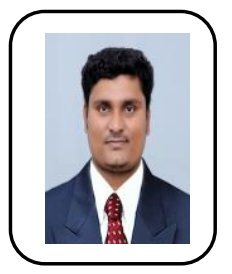

\section{AUTHORS PROFILE}

M.S. Abilash has received master degree in $\mathrm{CAD} / \mathrm{CAM}$ from Kumaraguru College of Engineering \& Technology, Coimbatore, India. He is currently as the Research Scholar at Kalasalingam Academy of Research and Education in the Department of Mechanical Engineering.. He had 7 years of Academic Experience

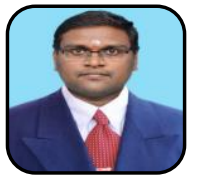

Dr.V. Arumugaprabu is working as Associate Professor in the Department of Mechanical Engineering, School of Automotive and Mechanical Engineering, Kalasalingam Academy of Research and Education, Krishnankoil, Tamilnadu, India. He graduated B.E in Mechanical Engineering at AKCE in 2005, graduated M.E in CAD/CAM at Mepco Schlenk Engg., college in 2007, graduated Ph.D in Composite Materials in 2014 at Kalasalingam University, krishnanakoil. He has very vast research experience in the field of composite materials with nearly 35 publications in various reputed SCI Journals.

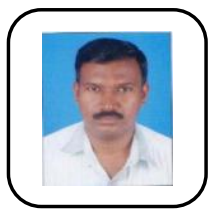

Dr.C.Bennet is an Associate Professor in the Department of Mechanical Engineering, Kalasalingam Academy of Research and Education, Krishnankoil, Tamilnadu, India. His current area of research includes polymer matrix composites, characterization and its studies. $\mathrm{He}$ has published a number of papers in journal of national/international repute and presented a number of papers in various conferences/symposia in India and abroad. He is presently guiding a number of master/doctoral research scholars. Dr.C.Bennet is the corresponding author and can be contacted at: benutha24@rediffmail.com 